\title{
PENGEMBANGAN PENGHAPUS PAPAN TULIS PUTIH MENGGUNAKAN METODE TRIZ
}

\author{
Faisal Arif Nurgesang ${ }^{1)}$, Dion Armayudha Hatmanto ${ }^{2)}$ \\ Program Studi Teknik Mesin, Fakultas Teknologi Industri, Universitas Islam Indonesia,2) \\ Jalan Kaliurang Km 14.5 Sleman, Yogyakarta, 55584, Indonesia \\ E-Mail : faisal.arif.nurgesang@uii.ac.id ${ }^{l)}$
}

\begin{abstract}
ABSTRAK
Di Fakultas Teknologi Industri Universitas Islam Indonesia, papan tulis putih digunakan sebagai sarana pada proses pembelajaran di kelas. Umumnya, para pengajar menggunakan spidol jenis nonpermanen agar mudah dibersihkan dengan penghapus. Masalah yang terjadi adalah jika penghapus ini sering digunakan maka kemampuannya akan berkurang. Hal ini disebabkan oleh banyaknya tinta spidol yang telah menempel pada kain penghapus sehingga sebagian tinta yang tidak dapat menempel berbentuk butiran-butiran halus akhirnya terjatuh dan terkumpul pada penampung kotoran. Butiranbutiran halus ini dapat mengotori pakaian, tangan dan bagian tubuh lainnya. Selain itu, terdapat sisasisa tinta spidol pada papan tulis yang dapat mengganggu untuk menuliskan materi berikutnya. Namun untuk mengatasinya, terdapat sebuah kontradiksi yaitu jika sebuah penghapus sering digunakan maka kemampuannya akan berkurang. Untuk mengeliminir kontradiksi tersebut, telah digunakan sebuah metode pemecahan masalah yang tersistematis yaitu metode TRIZ. Metode ini membantu memberikan solusi melalui prinsip preliminary action. Prinsip ini diwujudkan dengan menambahkan mekanisme penyemprot yang digunakan sesaat sebelum proses menghapus dilakukan. Pengujian kemampuan penghapus dilakukan pada papan tulis putih dengan arsiran tinta spidol berukuran $50 \times 50 \mathrm{~cm}$. Hasilnya menunjukkan bahwa penghapus baru hasil pengembangan mampu mengikat lebih banyak tinta spidol dan dapat mengapus secara tuntas sehingga dapat menuliskan materi berikutnya dengan jelas.
\end{abstract}

Kata kunci: Pengembangan Penghapus; Penghapus Papan Tulis Putih; TRIZ

\section{DEVELOPMENT OF WHITEBOARD ERASER USING TRIZ METHOD}

\begin{abstract}
In Faculty of Industrial Technology Islamic University of Indonesia, whiteboards are used as a medium of learning in the classroom. Generally, instructors use non-permanent markers to make it easy to clean with an eraser. The problem that occurs is if this eraser is often used, the ability will decrease. This is caused by the large amount of ink markers that have been attached to the eraser cloth so that some ink that can not stick in the form of fine grains eventually falls and collects in the dirt container. These fine grains can contaminate clothes, hands, and other body parts. In addition, there are remnants of ink markers on the board that can hinder to write the next material. But to overcome this, there is a contradiction that is if an eraser is often used, the ability will decrease. To eliminate this contradiction, a systematic method of problem solving was used, namely TRIZ method. This method helps to provide solutions through the principle of preliminary action. This principle was realized by adding a spray mechanism that is used just before the erasing process is carried out. Testing the ability of the eraser was done on a whiteboard with ink markers with the size of $50 \times 50$ $\mathrm{cm}$. The results show that the new eraser that has been developed is able to bind more ink markers and can completely erase so that it can write the next material clearly.
\end{abstract}

Keywords: Development of Eraser; Whiteboard Eraser; TRIZ 


\section{PENDAHULUAN}

Papan tulis putih adalah papan yang terbuat dari triplek melamin atau formika yang memiliki permukaan halus dan licin. Papan tulis ini banyak digunakan sebagai sarana kegiatan pembelajaran di kelas. Papan tulis ini telah lama menggantikan papan tulis hitam karena dianggap lebih bersih dan modern. Namun ternyata, penggunaan kapur tulis pada papan tulis hitam lebih aman jika dibandingkan penggunaan spidol pada papan tulis putih. Dikutip dari Detikhealth, spidol lebih berbahaya dibandingkan dengan kapur tulis. Kapur tulis yang telah lama ditinggalkan dibuat dari senyawa $\mathrm{CaCo}_{3}$ yaitu bentuk olahan dari kapur alam yang menghasilkan butiran-butiran kasar apabila digunakan untuk menulis. Butiran-butiran kasar tersebut lebih mudah untuk disaring oleh bulu-bulu halus hidung manusia. Selain itu, spidol yang banyak digunakan selama ini mengandung xylene yaitu bahan kimia yang menimbulkan aroma khas pada spidol dan juga banyak digunakan pada cat, thinner dan pernis (DetikHealth, 2011).

Menurut hasil studi yang dikutip dari Toxological Profile for Xylene, Agency for Toxic Substances and Disease Registry, efek jangka pendek dari xylene adalah dapat menimbulkan gangguan pada kulit, mengganggu pernapasan, pusing, sakit kepala dan kehilangan memori jangka pendek (Neghab \& Stacey, 1997; Nies \& Korinth, 2008). Sedangkan efek jangka panjang dapat menyebabkan kerusakan otak permanen dan kerusakan hati, ginjal dan sistem saraf pusat (Revilla et al., 2007; Neghab, Hosseinzadeh, \& Hassanzadeh, 2015; Gerberding, 2007).

Di Fakultas Teknologi Industri Universitas Islam Indonesia, proses belajar mengajar telah seluruhnya menggunakan papan tulis putih sebagai media untuk menuliskan materi yang diajarkan. Pada umumnya, para pengajar menggunakan spidol jenis non-permanen untuk menuliskan materi agar mudah dibersihkan dengan penghapus. Bagian utama penghapus ini terbuat dari busa yang dibungkus dengan kain.

Permasalahan yang terjadi adalah jika penghapus ini sering digunakan, kemampuan kain untuk menghapus tinta spidol pada papan tulis menjadi berkurang. Hal ini diakibatkan oleh banyaknya tinta spidol yang telah menempel pada kain sehingga sebagian tinta yang tidak dapat menempel berbentuk butiran-butiran halus akhirnya terjatuh dan terkumpul pada penampung kotoran. Butiran-butiran halus ini dapat mengotori pakaian, tangan dan bagian tubuh pengajar yang cukup sulit untuk dibersihkan. Selain itu, terdapat sisa-sisa tinta spidol yang tidak hilang secara tuntas pada permukaan papan tulis sehingga dapat mengganggu untuk menuliskan materi berikutnya.

Salah satu usaha untuk mengatasi permasalahan ini adalah dengan meningkatkan kemampuan penghapus agar dapat digunakan untuk waktu yang lebih lama namun butiran-butiran halus tetap menempel pada kain agar tidak terjatuh pada penampung kotoran. Oleh karena itu, diperlukan sebuah solusi guna mengatasi hal tersebut karena kembali ke papan tulis hitam sulit untuk dilakukan karena ketersediaan jenis papan ini dan kapur tulis yang mulai jarang ditemukan.

Untuk mengurangi dampak akibat dari butiran-butiran halus tinta spidol, dapat dilakukan penelitian dengan berfokus pada pengembangan sebuah penghapus baru dengan kriteria yaitu:

1. Mampu mengikat lebih banyak butiranbutiran halus tinta spidol agar tidak banyak yang terjatuh pada bagian penampung kotoran.

2. Mampu membersihkan sisa - sisa tinta spidol dengan tuntas.

Namun untuk meningkatkan kemampuan penghapus, terdapat sebuah kontradiksi yaitu jika penghapus sering digunakan, maka kemampuan kain untuk menghapus menjadi berkurang yang berakibat pada banyaknya butiran - butiran 
halus terjatuh pada bagian penampung kotoran.

Untuk mewujudkan penghapus tersebut, dibutuhkan sebuah metode yang praktis dan kreatif untuk membantu memunculkan sebuah ide. Salah satu metode yang dapat digunakan untuk memunculkan solusi ide yang inovatif dan kreatif terhadap permasalahan yang terdapat sebuah kontradiksi adalah metode TRIZ. TRIZ merupakan sebuah metode brilian yang berguna untuk memunculkan kreativitas dari masalah-masalah yang memiliki kontradiksi (Gadd, 2011; Bertoncelli, Mayer, \& Lynass, 2016; Chechurin \& Borgianni, 2016). Metode ini memberikan sebuah pendekatan logis yang tersistematis untuk berinovasi dengan menawarkan beberapa pilihan solusi dengan mengeliminir kontradiksi (Ilevbare, Probert, \& Phaal, 2013; Chai, Zhang, \& Tan, 2005; Czinki \& Hentschel, 2016).

Hasil usulan solusi dari TRIZ diperlukan sebuah tahapan untuk menerjemahkan ide yang diusulkan yang disebut brainstorming. Brainstorming adalah proses memunculkan ide yang dapat dilakukan dengan cara (1) menghindari kritik, (2) menuliskan semua hal yang muncul dalam pikiran, (3) mencoba menghasilkan banyak ide tanpa memikirkan kualitas, dan (4) mencoba menggabungkan ide-ide (Chang, Chien, Yu, Chu, \& Chen, 2016; Göçmen \& Coşkun, 2019; Lu, Qiao, \& Hao, 2019; Paulus, Nakui, Putman, \& Brown, 2006).

Untuk mewujudkan hasil brainstorming pada proses pengembangan produk, ide-ide yang diperoleh dapat dituangkan dengan membuat sketsa sederhana. Sketsa merupakan representasi bergambar yang sepenuhnya mendefinisikan satu konsep, desain atau ide (Hartson, Pyla, Hartson, \& Pyla, 2019; Martin-erro, Dominguez, \& Espinosa, 2016).
Sebuah sketsa dapat diteruskan untuk dibuat menjadi sebuah desain konsep yang dapat digunakan untuk mengkomunikasikan karya kepada calon pengguna atau masyarakat umum (Self, 2019; Shroyer, Lovins, Turns, Cardella, \& Atman, 2018; Wetter-Edman, Vink, \& Blomkvist, 2018). Desain konsep tersebut kemudian dapat diwujudkan menjadi sebuah purwarupa. Proses perwujudan purwarupa dalam era teknologi sekarang ini dapat dilakukan dengan menggunakan teknologi 3D printing. 3D printing merupakan teknologi yang dapat digunakan untuk membuat benda padat tiga dimensi dari suatu desain digital (Azammi, Sapuan, Ishak, \& Sultan, 2018; Ford \& Minshall, 2019). Teknologi ini dapat digunakan dalam proses pengembangan penghapus pada penelitian yang dilakukan.

Penelitian ini bertujuan untuk mengembangkan penghapus baru yang lebih baik dibandingkan dengan penghapus yang selama ini digunakan menggunakan metode TRIZ dengan mengeliminir kontradiksi yang terjadi. Diharapkan penelitian ini dapat menghasilkan penghapus baru yang mampu mengatasi permasalahan yang terjadi.

\section{METODOLOGI}

\subsection{Pemunculan Ide}

Penelitian ini diawali dengan memunculkan ide dari kontradiksi yang teridentifikasi terhadap fitur yang ingin dinaikan (improving feature) dan fitur yang tidak diinginkan (worsening feature). Terdapat 39 kontradiksi TRIZ yang digunakan untuk memperoleh usulan 40 prinsip TRIZ seperti tercantum pada Tabel 1. 
Tabel 1. 39 Kontradiksi TRIZ

\begin{tabular}{|c|c|c|c|}
\hline No. & Principles & No. & Principles \\
\hline 1 & Wheight of moving object & 21 & Power \\
\hline 2 & Wheight of stationary object & 22 & Loss of energy \\
\hline 3 & Length of moving object & 23 & Loss of substance \\
\hline 4 & Length of stationary object & 24 & Loss of information \\
\hline 5 & Area of moving object & 25 & Loss of time \\
\hline 6 & Area of stationary object & 26 & Quantity of substance \\
\hline 7 & Volume of moving object & 27 & Reliability \\
\hline 8 & Volume of stationary object & 28 & Measurement accuracy \\
\hline 9 & Speed & 29 & Manufacturing precision \\
\hline 10 & Force & 30 & $\begin{array}{c}\text { External harm affects the } \\
\text { object }\end{array}$ \\
\hline 11 & Stress or Pressure & 31 & $\begin{array}{l}\text { Object generated-harmful } \\
\text { factor }\end{array}$ \\
\hline 12 & Shape & 32 & Ease of manufacture \\
\hline 13 & $\begin{array}{c}\text { Stability of the object's } \\
\text { composition }\end{array}$ & 33 & Ease of operation \\
\hline 14 & Strength & 34 & Ease of repair \\
\hline 15 & $\begin{array}{c}\text { Duration of action by a } \\
\text { moving object }\end{array}$ & 35 & Adaptability of versality \\
\hline 16 & $\begin{array}{c}\text { Duration of action by a } \\
\text { stationary object }\end{array}$ & 36 & Device complexity \\
\hline 17 & Temperature & 37 & $\begin{array}{c}\text { Difficulity of deeteting and } \\
\text { measuring }\end{array}$ \\
\hline 18 & Illumination intensity & 38 & Extent of automation \\
\hline 19 & $\begin{array}{c}\text { Use of energy by moving } \\
\text { object }\end{array}$ & 39 & Productivity \\
\hline 20 & $\begin{array}{c}\text { Use of energy by a } \\
\text { stationary object }\end{array}$ & & \\
\hline
\end{tabular}

\begin{tabular}{|c|c|c|c|c|c|c|c|}
\hline \multicolumn{2}{|c|}{$\begin{array}{l}\text { Worsting } \\
\text { Fenture IIL }\end{array}$} & 1 & 7 & 33 & 36 & 38 & 39 \\
\hline & $\begin{array}{l}\text { Inquoving } \\
\text { Feature }\end{array}$ & 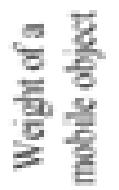 & $\begin{array}{l}E \\
3 \\
\xi \\
\xi\end{array}$ & $\frac{y}{E} \underline{z}$ & $\frac{2}{\frac{3}{2}}$ & 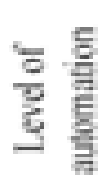 & $\frac{2}{3} \frac{2}{3}$ \\
\hline 1 & $\begin{array}{l}\text { Weight of a } \\
\text { mobtle obset }\end{array}$ & & $\begin{array}{r}29.2 \\
40.28\end{array}$ & $\begin{array}{l}35.3 \\
2.24\end{array}$ & $\begin{array}{l}26.30 \\
36.34\end{array}$ & $\begin{array}{l}26.35 \\
18.19\end{array}$ & $\begin{array}{l}35.3 \\
24.37\end{array}$ \\
\hline 7 & $\begin{array}{c}\text { Nohene of } \\
\text { mobile ot }\end{array}$ & $\begin{array}{l}226 \\
29.40\end{array}$ & & $\begin{array}{l}15.13 \\
30.12\end{array}$ & 26. & $\begin{array}{l}35.34 \\
16.24\end{array}$ & $\begin{array}{l}10,6 \\
234\end{array}$ \\
\hline 33 & $\begin{array}{c}\text { Comenuence of } \\
\text { ase }\end{array}$ & $\begin{array}{l}25,2 \\
13,15\end{array}$ & $\begin{array}{l}1.16 \\
3515\end{array}$ & & $\begin{array}{l}32,26 \\
12,17\end{array}$ & $\begin{array}{l}1,34 \\
12,3\end{array}$ & $\begin{array}{c}15,1 \\
28\end{array}$ \\
\hline 36 & $\begin{array}{c}\text { Complexity of } \\
\text { a devece }\end{array}$ & $\begin{array}{l}26,30 \\
34,36\end{array}$ & $\begin{array}{c}3426 \\
6\end{array}$ & $\begin{array}{c}27,9 \\
26,24\end{array}$ & & $\begin{array}{c}15,1 \\
24\end{array}$ & $\begin{array}{c}1217 \\
28\end{array}$ \\
\hline 38 & $\begin{array}{c}\text { Level of } \\
\text { antomation }\end{array}$ & $\begin{array}{l}28,26 \\
18,35\end{array}$ & $\begin{array}{c}35.13 \\
16\end{array}$ & $\begin{array}{l}1,12 \\
34.3\end{array}$ & $\begin{array}{c}15.24 \\
10\end{array}$ & & $\begin{array}{l}512 \\
35.26\end{array}$ \\
\hline 8 & $\begin{array}{l}\text { Capocityl } \\
\text { productivity }\end{array}$ & $\begin{array}{l}35,26 \\
24.37\end{array}$ & $\begin{array}{c}26 \\
3410\end{array}$ & $\begin{array}{l}1,28 \\
7,19\end{array}$ & $\begin{array}{l}12.17 \\
28,24\end{array}$ & $\begin{array}{l}5.12 \\
35.26\end{array}$ & \\
\hline
\end{tabular}

Gambar 1. Tabel Kontradiksi TRIZ

Sumber: Yuan (2004) 
Tabel 2. 40 Prinsip TRIZ

\begin{tabular}{cccc}
\hline No. & Principles & No. & Principles \\
\hline 1 & Segmentation & 21 & Skipping \\
2 & Taking out & 22 & Blessing in disguise \\
3 & Local quality & 23 & Feedback \\
4 & Asymetry & 24 & Intermediary \\
5 & Merging & 25 & Self-service \\
6 & Universality & 26 & Copying \\
7 & Nested doll & 27 & Cheap short-living object \\
8 & Anti-weight & 28 & Mechanic substitution \\
9 & Preliminary anti-action & 29 & Pneumatics and \\
& & & Hydraulics \\
10 & Preliminary action & 30 & Thin films \\
11 & Beforehand cushioning & 31 & Porous materials \\
12 & Equipotentiality & 32 & Color changes \\
13 & The other way round & 33 & Homogenity \\
14 & Curvature & 34 & Discarding and recovering \\
15 & Dinamics & 35 & Parameter changes \\
16 & Partial or excessive action & 36 & Phase transitions \\
17 & Another dimension & 37 & Thermal expansion \\
18 & Mechanical vibration & 38 & Strong oxidants \\
19 & Periodic action & 39 & Inert atmosphere \\
20 & Continuity of useful action & 40 & Composite materials \\
\hline
\end{tabular}

Tabel 3. Pengaturan Parameter Untuk Pembuatan Purwarupa

\begin{tabular}{ccc}
\hline No. & Parameter & Ukuran \\
\hline 1 & Tinggi layer & $0,1 \mathrm{~mm}$ \\
2 & Ketebalan shell & $0,6 \mathrm{~mm}$ \\
3 & Fill density & $30 \%$ \\
4 & Flow & $100 \%$ \\
\hline
\end{tabular}

Kontradiksi yang telah diidentifikasi kemudian dimasukkan pada tabel kontradiksi TRIZ seperti ditunjukkan pada Gambar 1.

Dari hasil persilangan menggunakan tabel kontradiksi TRIZ, diperoleh usulan berupa 40 prinsip TRIZ yang dapat digunakan untuk proses brainstorming guna memunculkan ide seperti ditunjukkan pada Tabel 2.

Usulan-usulan yang diperoleh sesuai dengan 40 prinsip TRIZ kemudian dilakukan proses brainstorming yaitu membuat beberapa alternatif konsep penyelesaian masalah yang mewakili usulan yang diberikan.

\subsection{Pembuatan Desain Konsep}

Desain konsep dilakukan dengan membuat sketsa disertai dengan fitur-fitur yang ditawarkan. Sketsa dibuat secara manual menggunakan pensil pada sebuah kertas gambar ukuran A3.

\subsection{Pemilihan Desain Konsep}

Pemilihan desain konsep dilakukan guna mendapatkan desain yang paling disukai dan memenuhi kriteria yang diperlukan oleh responden. Responden pada proses pemilihan desain konsep ini adalah dosen dan asisten laboratorium di Fakultas Teknologi Industri Universitas Islam Indonesia yang berjumlah total 20 orang. 


\subsection{Pembuatan Purwarupa}

Purwarupa dibuat menggunakan mesin 3D printer (Prusia, i3) dengan material PLA berdiameter $1,75 \mathrm{~mm}$ dengan pengaturan parameter seperti tercantum pada Tabel 3.

Hasil dari 3D Printing kemudian dilakukan penghalusan serta pendempulan agar memiliki permukaan yang halus. Untuk proses finalisasi, dilakukan pengecatan menggunakan cat dengan warna identitas Universitas Islam Indonesia yaitu warna Biru.

\subsection{Pengujian Kemampuan Penghapus}

Pengujian dilakukan pada sebuah papan tulis putih menggunakan spidol nonpermanen dengan membuat garis-garis arsir saling menyilang untuk (a) Pengujian penghapus yang selama ini digunakan dan (b) Pengujian penghapus hasil pengembangan dengan ukuran $50 \mathrm{~cm} \times 50$ cm seperti dapat dilihat pada Gambar 2 .

Pengujian dilakukan dengan menghapus area uji sebanyak lima kali pengulangan pada area dan beban arsiran spidol yang sama. Sebelum dilakukan pengujian, area yang diuji pada papan tulis putih telah dipastikan memiliki tingkat kebersihan yang sama. Selain itu, kain pada kedua penghapus juga masih dalam keadaan bersih.

\section{HASIL DAN PEMBAHASAN \\ 3.1. Pemunculan Ide}

Pada pengembangan penghapus ini, fitur yang diinginkan adalah kemampuan untuk menghapus secara terus menerus dan fitur yang tidak diinginkan adalah butiran-butiran halus tinta spidol terjatuh pada penampung kotoran. Berdasarkan 39 kontradiksi TRIZ, fitur yang ingin dinaikkan sesuai pada salah satu dari 39 kontradiksi TRIZ yaitu Productivity dan fitur yang tidak diinginkan sesuai dengan Loss of Substance. Dari kontradiksi tersebut, kemudian dimasukkan pada tabel kontradiksi TRIZ untuk memperoleh usulan dari 40 prinsip TRIZ. Persilangan dari fitur yang diinginkan dan tidak diinginkan ditunjukkan pada Gambar 3.

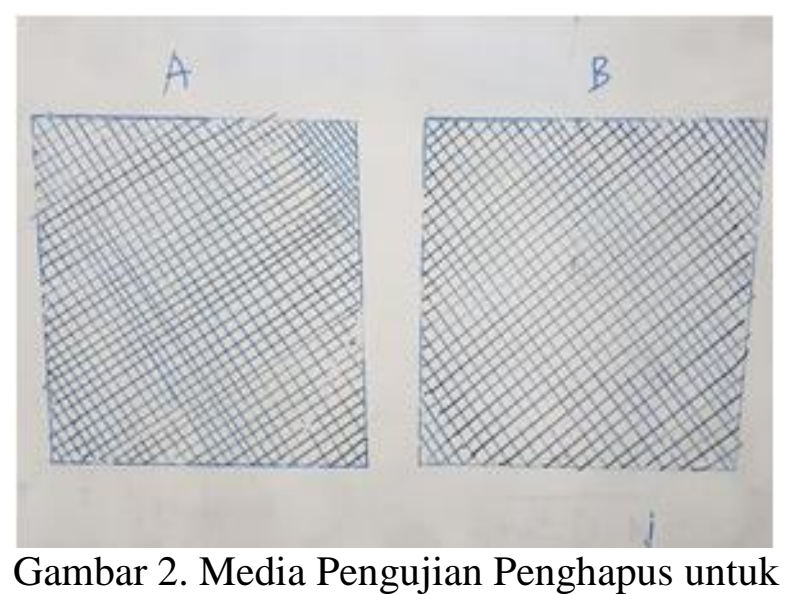

(a) Penghapus yang Selama Ini Digunakan dan (b) Penghapus Hasil Pengembangan

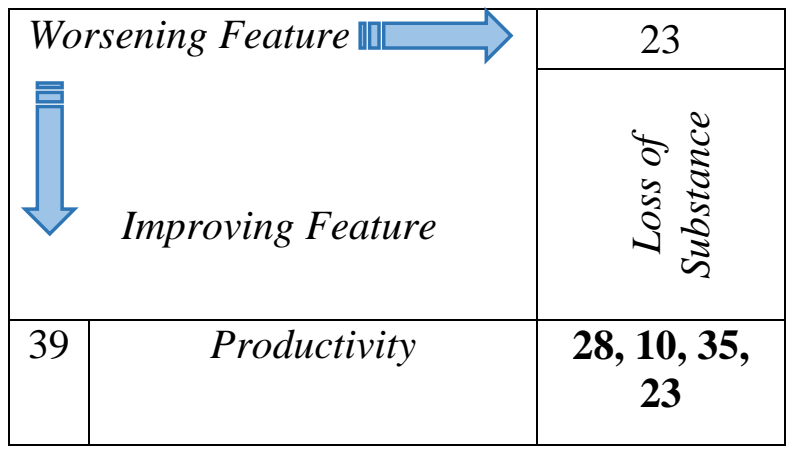

Gambar 3. Persilangan Kontradiksi 
Dari hasil persilangan diatas, diperoleh usulan yaitu prinsip TRIZ No 28. Mechanic Substitution, No 10. Preliminary Action, No 35. Parameter Changes, dan No 23. Feedback. Berdasarkan usulan - usulan tersebut, dilakukan brainstorming untuk memunculkan ide kreatif agar dapat menyelesaikan permasalahan yang dihadapi.

Untuk memudahkan perolehan ide berdasarkan usulan yang disajikan oleh TRIZ, masing-masing usulan tersebut dilakukan identifikasi ide apakah yang mungkin muncul untuk menyelesaikan permasalahan yang terjadi. Pemilihan ide diawali dengan memunculkan ide terhadap masing-masing usulan.

Agar memudahkan untuk memunculkan ide, terlebih dahulu dipahami arti dari masing-masing usulan TRIZ yang diperoleh. Mechanic substitution adalah mengganti sistem mekanik menjadi sistem lain misalnya mengubah menjadi elektrik dan magnetik. Preliminary action adalah melakukan sesuatu sebelum aktivitas utama dilakukan. Parameter changes adalah mengubah parameter dari objek atau sistemnya dari solid menjadi liquid atau gas. Sedangkan feedback adalah peninjauan ulang proses agar dapat meningkatkan hasil (Gadd, 2011). Tabel 4 merupakan ide - ide penyelesaian masalah berdasarkan usulan TRIZ.

Setelah memperoleh ide-ide dari masing-masing usulan TRIZ diatas, kemudian dilakukan analisis kemungkinan untuk menentukan ide mana yang mungkin untuk diwujudkan. Salah satu pertimbangan untuk mewujudkan ide yang relatif mudah yaitu pertimbangan biaya. Berdasarkan observasi dan perkiraan, telah diidentifikasi biaya yang dibutuhkan untuk mewujudkan masing-masing ide yang diusulkan seperti ditunjukkan pada Tabel 5.

Berdasarkan identifikasi seperti tersaji pada Tabel 5 dan melihat permasalahan yang terjadi, ide yang paling mudah dan murah untuk diwujudkan adalah membuat penghapus yang dapat menyemprotkan cairan berdasarkan usulan TRIZ No 10 . Preliminary action. Ide yang diperoleh adalah dengan memberikan suatu cairan tertentu sebelum dilakukan proses utama yaitu menghapus spidol seperti dijelaskan melalui skema pada Gambar 4.

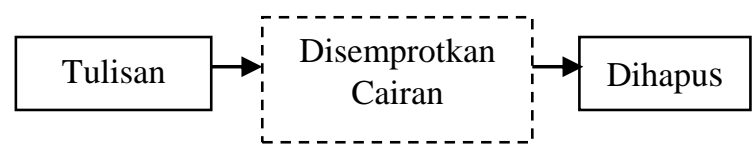

Gambar 4. Skema Proses Menghapus

Cairan yang dipilih untuk disemprotkan sebelum proses menghapus adalah cairan pembersih kaca merk Cling. Proses penyemprotan cairan pembersih kaca bertujuan untuk mengikat butiran-butiran halus tinta spidol yang telah mengering dan akan jatuh pada bagian penampung kotoran. Dengan menyemprotkan cairan, butiranbutiran halus tersebut dapat menempel lebih banyak pada kain penghapus hasil pengembangan.

\subsection{Pembuatan Desain Konsep}

Setelah memperoleh ide dengan menyemprotkan cairan pembersih kaca sebelum menghapus spidol, dibuat beberapa konsep desain melalui gambar sketsa. Telah dibuat empat buah gambar sketsa menggunakan pensil pada kertas gambar A3 yaitu model $\mathrm{A}$, model $\mathrm{B}$, model $\mathrm{C}$, dan model D. Sketsa penghapus model A dapat dilihat pada Gambar 5.

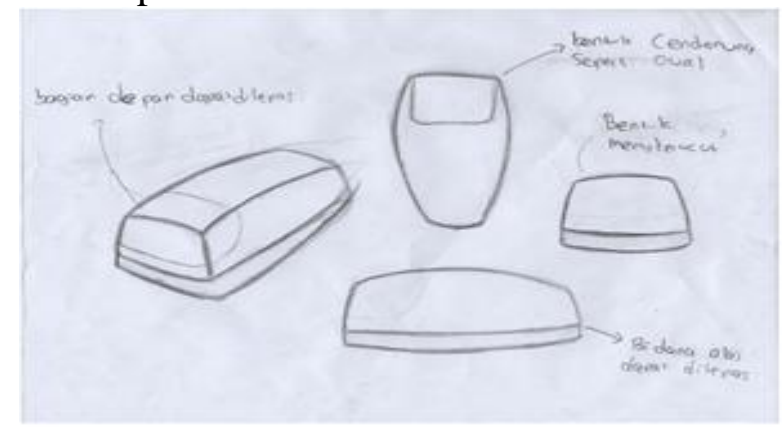

Gambar 5. Sketsa Penghapus Model A 
Tabel 4. Ide - Ide Penyelesaian Masalah Berdasarkan Usulan TRIZ

\begin{tabular}{|c|c|c|}
\hline No & Usulan TRIZ & Ide \\
\hline 1 & Mechanic substitution & $\begin{array}{l}\text { Membuat papan tulis magnet dan spidol yang } \\
\text { mengandung serbuk besi. }\end{array}$ \\
\hline 2 & Preliminary action & $\begin{array}{l}\text { Membuat penghapus yang dapat menyemprotkan } \\
\text { cairan. }\end{array}$ \\
\hline 3 & Parameter changes & Membuat penghapus bertekanan. \\
\hline 4 & Feedback & $\begin{array}{l}\text { Membuat penghapus yang dapat menunjukkan } \\
\text { informasi bahwa penghapus belum membersihkan } \\
\text { secara tuntas. }\end{array}$ \\
\hline
\end{tabular}

Tabel 5. Perkiraan Biaya Untuk Mewujudkan Ide Berdasarkan Usulan TRIZ

\begin{tabular}{c|l|c|c}
\hline \multirow{2}{*}{ No } & \multicolumn{1}{|c|}{ Ide } & \multicolumn{2}{|c}{ Biaya } \\
\cline { 2 - 4 } 1 & $\begin{array}{l}\text { Membuat papan tulis magnet dan spidol } \\
\text { yang mengandung serbuk besi } \\
2\end{array}$ & $\begin{array}{l}\text { Membuat penghapus yang dapat } \\
\text { menyemprotkan cairan }\end{array}$ & $\checkmark$ \\
3 & $\begin{array}{l}\text { Membuat penghapus bertekanan } \\
\text { Membuat penghapus yang dapat } \\
\text { menunjukkan informasi bahwa } \\
\text { penghapus belum membersihkan secara } \\
\text { tuntas }\end{array}$ & $\checkmark$ & $\checkmark$ \\
\hline
\end{tabular}

Penghapus model A memiliki bentuk yang mudah digenggam dan apabila dilihat dari pandangan atas memiliki bentuk oval. Pada bagian ujung atas, terdapat sebuah mekanisme untuk membuka penyemprot. Untuk bagian bawah, dibuat sebuah mekanisme perekat agar kain yang berisi busa dapat dilepas sehingga apabila kain tersebut telah berkurang kemampuannya untuk mengikat butiran-butiran halus tinta spidol dapat dilepas dan dibersihkan sehingga dapat digunakan kembali.

Sketsa penghapus model B dapat dilihat pada Gambar 6. Penghapus model B memiliki bentuk bodi menyerupai mouse pada perangkat komputer. Penghapus model ini secara keseluruhan memiliki fitur yang sama dengan penghapus model A, namun untuk proses penyemprotan dapat dilakukan langsung dengan menekan tombol penyemprot yang menonjol keluar.

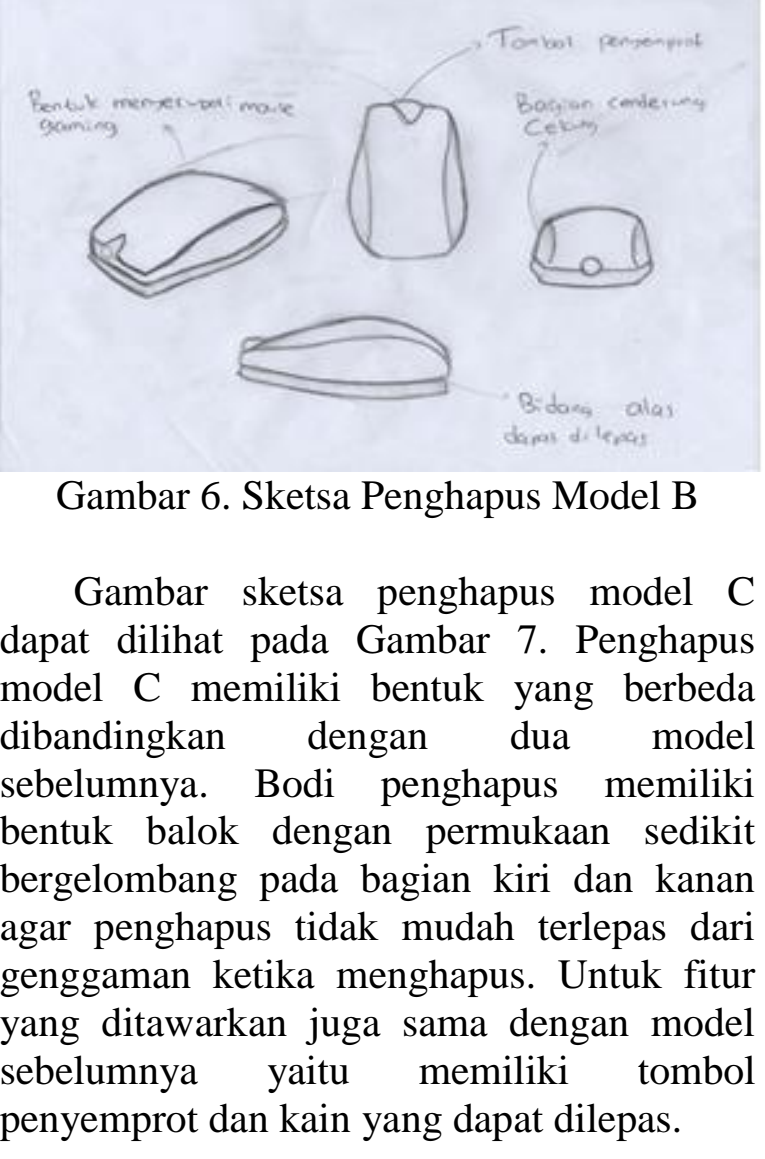




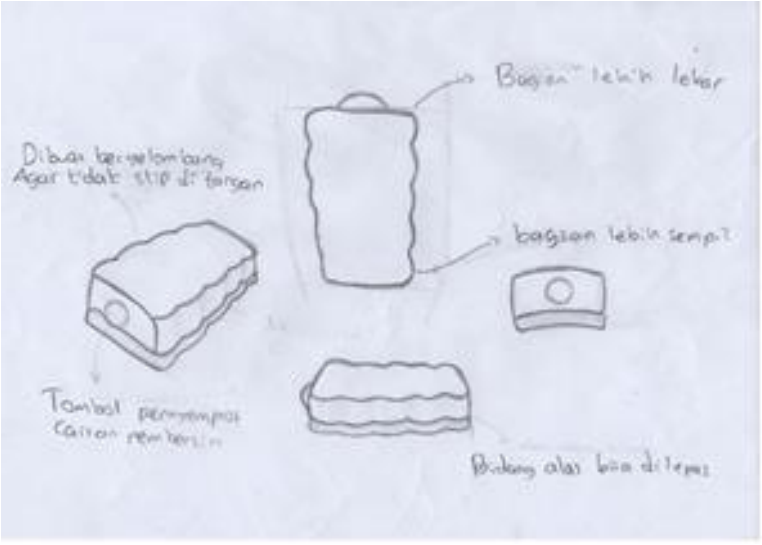

Gambar 7. Sketsa Penghapus Model C

Gambar sketsa penghapus model D dapat dilihat pada Gambar 8. Penghapus model ini secara bentuk memiliki kesamaan dengan penghapus model $\mathrm{B}$, namun mekanisme penyemprotan menggunakan sensor jarak.

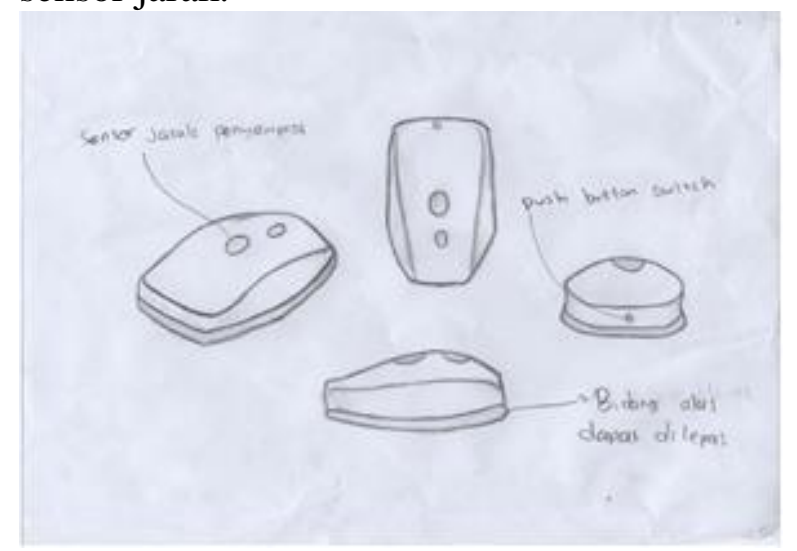

Gambar 8. Sketsa Penghapus Model D

\subsection{Pemilihan Desain Konsep}

Dari empat gambar sketsa yang telah dibuat, semua model tersebut dibuat menjadi bentuk yang lebih detail dan menarik secara visual melalui proses rendering menggunakan perangkat lunak Solidworks. Gambar 9-12 adalah hasil rendering model model penghapus tersebut.

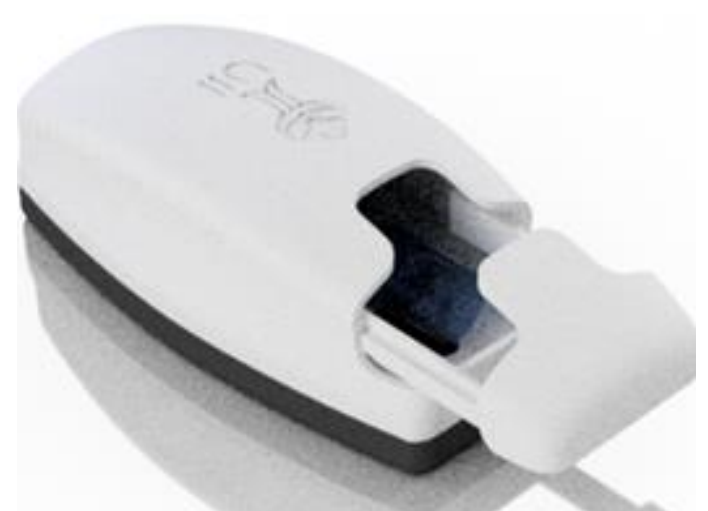

Gambar 9. Hasil Rendering Penghapus Model A

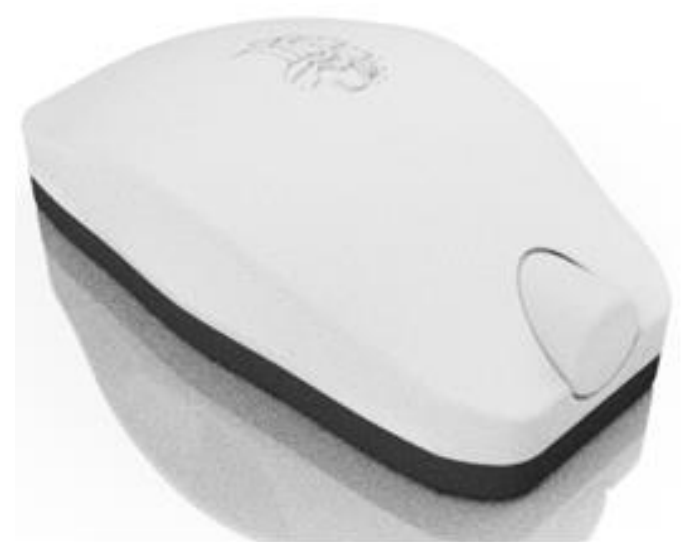

Gambar 10. Hasil Rendering Penghapus Model B

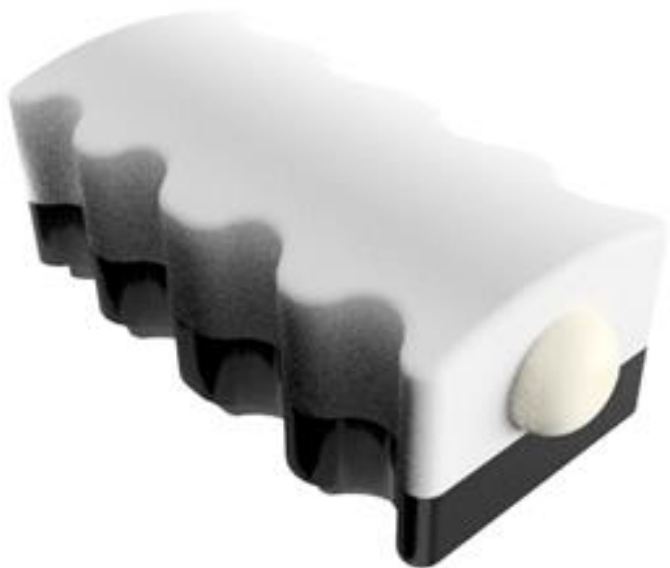

Gambar 11. Hasil Rendering Penghapus Model C 


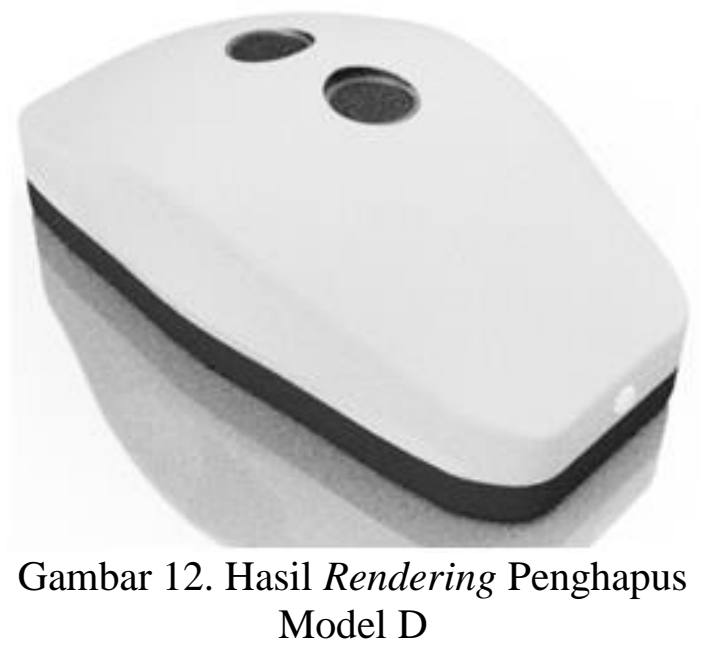

Dari empat model penghapus diatas kemudian ditawarkan kepada responden melalui kuisioner untuk mengetahui model yang paling diminati dan diharapkan agar dapat diwujudkan. Dari kusioner yang telah dilakukan diperoleh data seperti dapat dilihat pada Gambar 13.

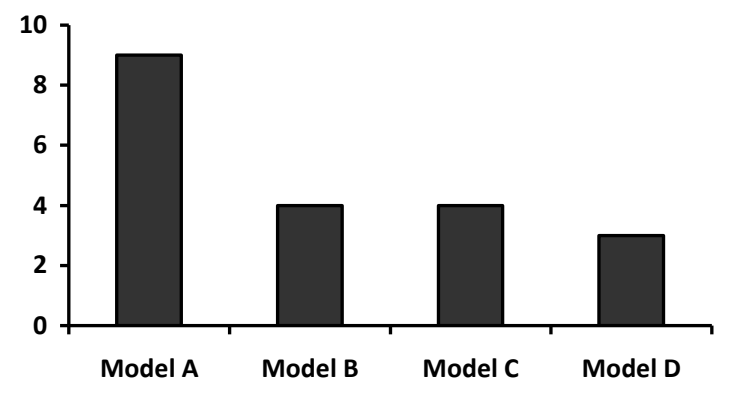

Gambar 13. Hasil Kuisioner

Seperti dapat dilihat pada Gambar 13, penghapus model A mendapatkan respon yang paling tinggi dibandingkan dengan model lainnya. Sebanyak sembilan responden menyukai model ini. Model yang disukai berikutnya adalah model $\mathrm{C}$ dan $\mathrm{D}$ dimana sama-sama memperoleh jumlah yang sama yaitu empat responden dan model yang paling sedikit dipilih oleh responden adalah model D.

\subsection{Pembuatan Purwarupa}

Berdasarkan kuisioner yang telah dilakukan untuk memilih model yang banyak disukai oleh responden, model dengan perolehan terbanyak dilanjutkan untuk diwujudkan menjadi sebuah purwarupa.
Gambar 14 berikut ini adalah detail komponen penghapus model A yang akan diwujudkan menggunakan mesin 3D printer.

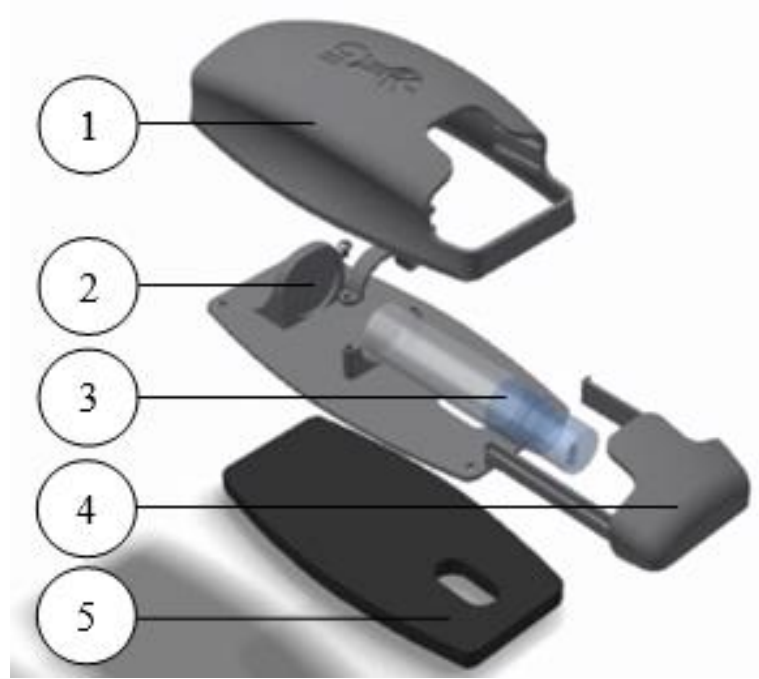

Keterangan: 1. Bodi atas penghapus, 2. Penahan botol penyemprot, 3. Botol penyemprot yang bersisi cairan pembersih kaca, 4. Penutup penyemprot dan 5. Bodi bawah penghapus

Gambar 14. Detail Komponen Penghapus Model A

Pembuatan purwarupa dilakukan menggunakan teknologi $3 D$ printing. Gambar 15 menunjukkan proses pemosisian dan pengaturan parameter penghapus model A pada perangkat lunak sebelum proses 3D printing dilakukan.

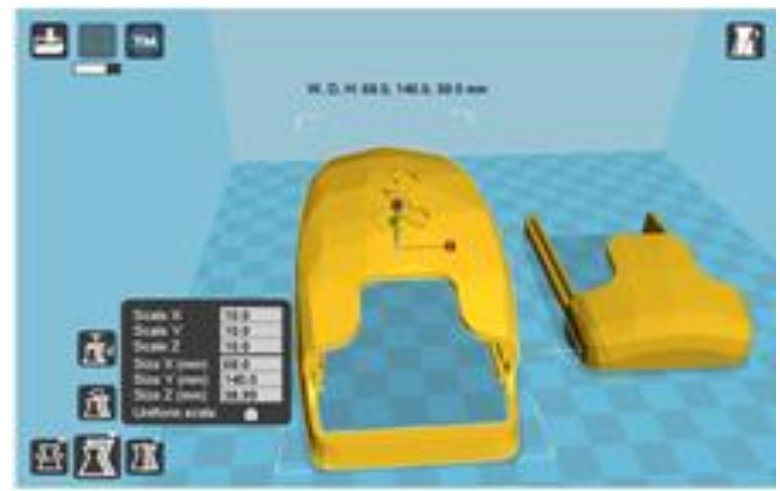

Gambar 15. Proses Pemosisian dan

Pengaturan Parameter

Gambar 16 menunjukkan proses pewujudan purwarupa menggunakan mesin 3D printer. Proses ini membutuhkan waktu selama 16 jam. 


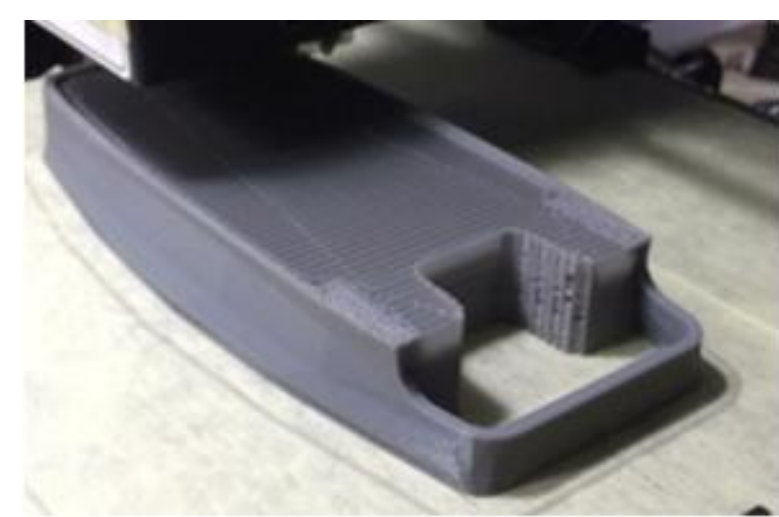

Gambar 16. Proses 3D Printing Penghapus

Model A

Setelah keseluruhan proses printing selesai untuk semua komponen, diperoleh hasil purwarupa seperti dapat dilihat pada Gambar 17.

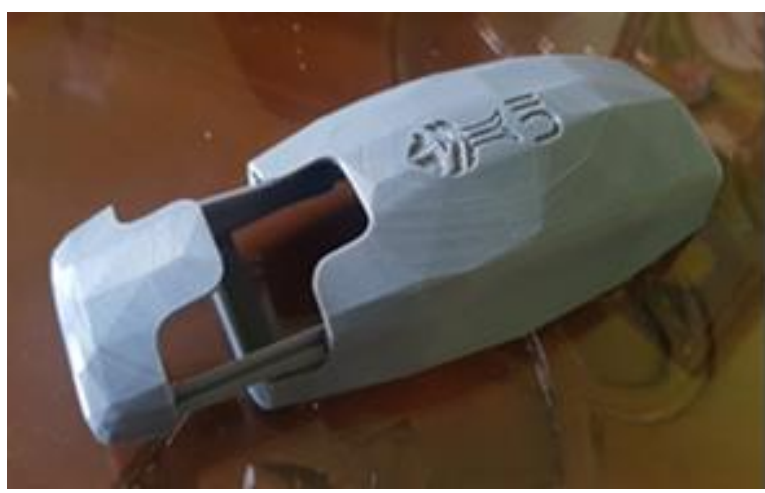

Gambar 17. Hasil 3D Printing Purwarupa Penghapus Model A

Dikarenakan permukaan hasil printing belum halus, diperlukan proses lanjutan yaitu melakukan pendempulan agar diperoleh permukaan yang halus dan rata. Setelah proses pendempulan dilakukan penjemuran dibawah sinar matahari langsung selama \pm 3 jam agar dempul menjadi keras sebelum dilakukan penghalusan menggunakan amplas. Penghalusan dilakukan menggunakan amplas nomor 600 untuk proses roughing dan amplas nomor 1000 untuk proses finishing. Gambar 18 menunjukkan proses pendempulan dan Gambar 19 menunjukkan proses penjemuran purwarupa penghapus model A.

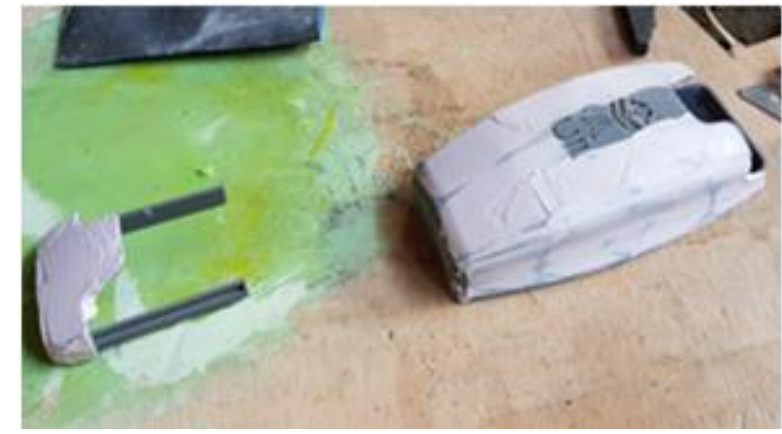

Gambar 18. Proses Pendempulan Purwarupa Penghapus Model A

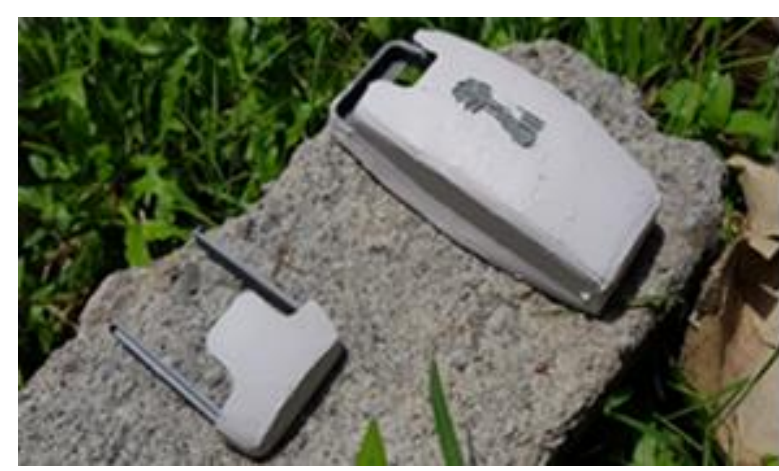

Gambar 19. Proses Penjemuran Purwarupa Penghapus Model A

Setelah permukaan penghapus dihaluskan, dilanjutkan dengan proses pengecatan. Warna yang dipilih untuk diterapkan pada penghapus adalah warna biru. Warna ini adalah warna khas Universitas Islam Indonesia. Gambar 20 menunjukkan proses pengecatan purwarupa penghapus model A.

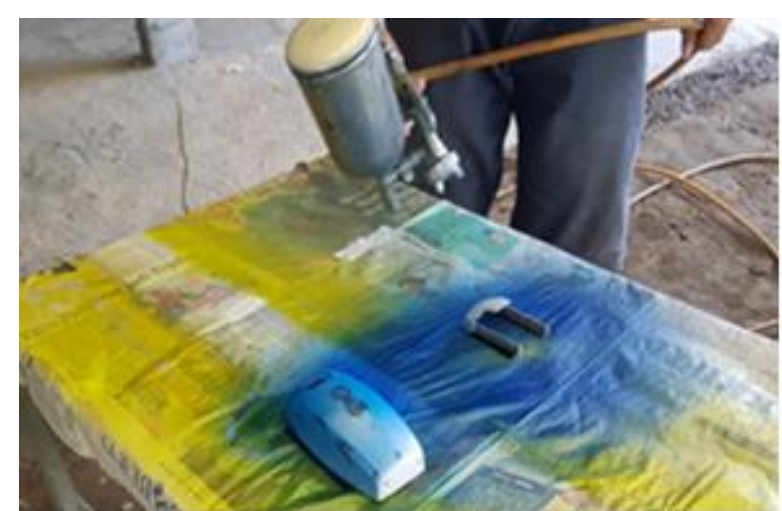

Gambar 20. Proses Pengecatan Purwarupa Penghapus Model A 
Proses pengecatan membutuhkan waktu \pm 1 jam kemudian diangin-anginkan selama \pm 6 jam hingga cat benar-benar kering. Gambar 21 menunjukkan purwarupa penghapus model A yang telah dirakit bersama dengan busa serta penyemprot didalamnya. Selain itu, penghapus ini memiliki mekanisme perekat untuk melepaskan kain yang berisi busa agar mudah dibersihkan sehingga dapat digunakan kembali.

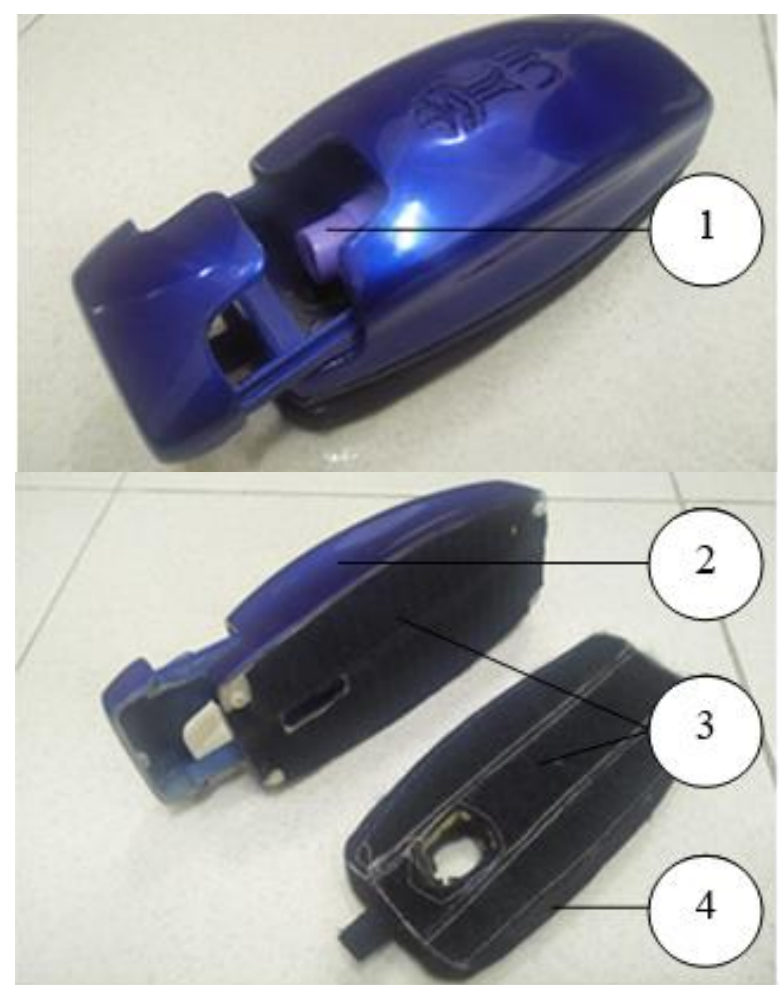

Keterangan: 1. Botol Penyemprot Berisi Cairan Pembersih Kaca, 2. Bodi Penghapus, 3. Perekat, dan 4. Busa Berbalut Kain

Gambar 21. Purwarupa Penghapus Model A

\subsection{Pengujian}

Pengujian

untuk mengetahui kemampuan penghapus dalam menghilangkan spidol pada papan tulis putih telah dilakukan. Gambar 22 menunjukkan permukaan papan tulis putih setelah dihapus menggunakan penghapus yang selama ini digunakan sedangkan Gambar 23 menunjukkan permukaan papan tulis putih setelah dihapus menggunakan penghapus hasil pengembangan.

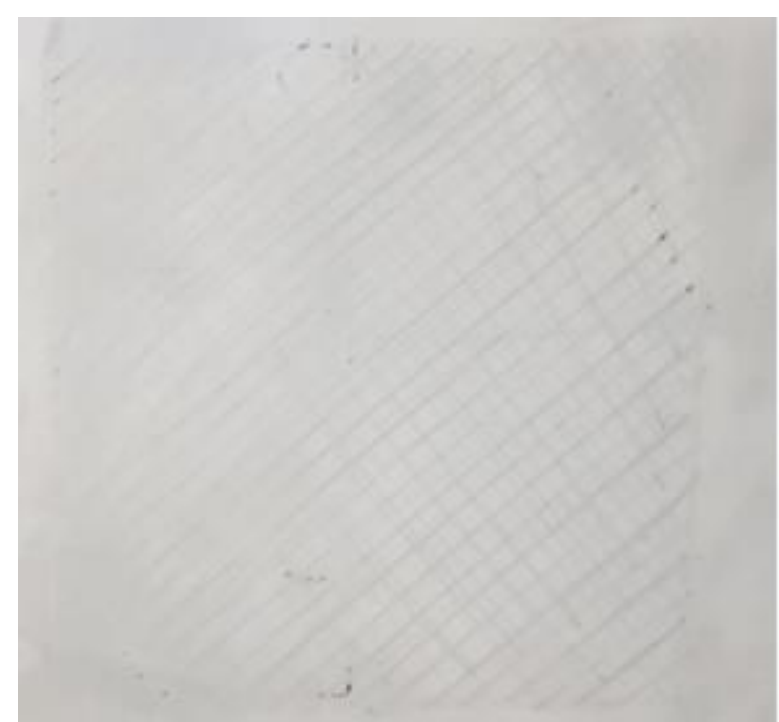

Gambar 22. Permukaan Papan Tulis Putih Setelah Dihapus Menggunakan Penghapus Yang Selama Ini Digunakan

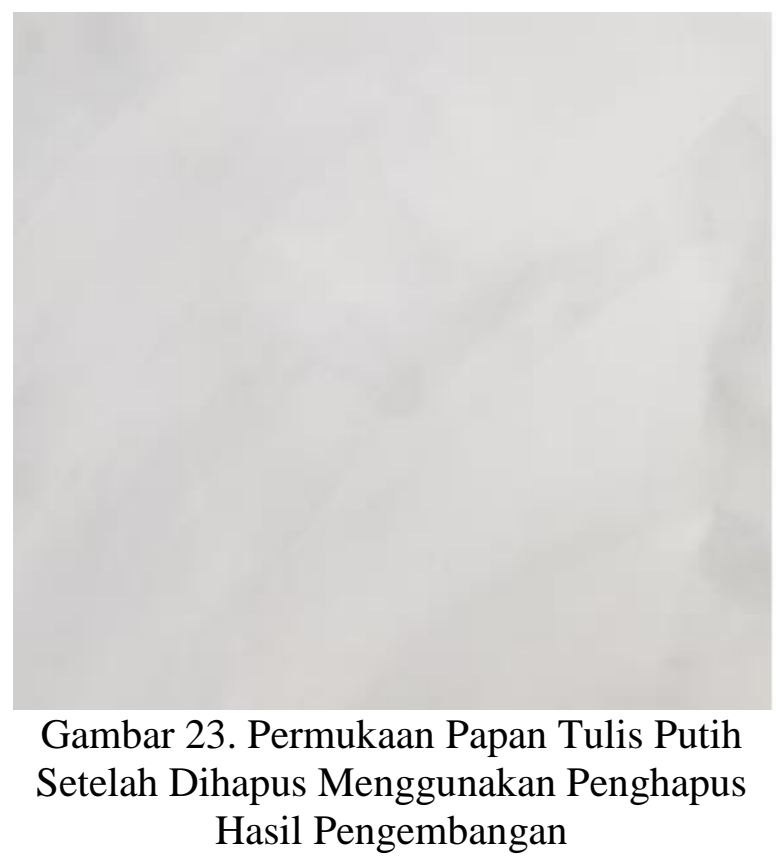

Dapat dilihat bahwa setelah dilakukan penghapusan pada area dan beban tinta spidol yang sama, penghapus hasil pengembangan dapat menghasilkan permukaan papan tulis putih lebih bersih dibandingkan dengan penghapus yang selama ini digunakan. Hal ini dikarenakan penerapan cairan sebelum dilakukan proses menghapus dapat meningkatkan kemampuan kain dan busa untuk lebih banyak mengikat tinta spidol. 


\section{KESIMPULAN}

Metode TRIZ telah berhasil membantu memunculkan ide yang kreatif secara sistematis untuk mengatasi permasalahan yang terjadi. Hasil pengembangan penghapus yang telah dilakukan dapat mengeliminir kontradiksi yang terjadi. Penghapus baru hasil pengembangan memiliki kemampuan mengikat lebih banyak tinta spidol agar tidak jatuh ke penampung kotoran. Selain itu, dari hasil pengujian yang dilakukan, penghapus yang dikembangkan dapat membersihkan permukaan papan tulis putih secara tuntas sehingga papan tulis dapat digunakan untuk menuliskan materi berikutnya dengan jelas.

\section{DAFTAR PUSTAKA}

Azammi, A. M. N., Sapuan, S. M., Ishak, M. R., \& Sultan, M. T. H. (2018). Conceptual design of automobile engine rubber mounting composite using TRIZ-Morphological chartanalytic network process technique. Defence Technology, Vol 14, No 4., 268-277.

Bertoncelli, T., Mayer, O., \& Lynass, M. (2016). Creativity, Learning Techniques and TRIZ, Vol 39, 191196.

Chai, K. H., Zhang, J., \& Tan, K. C. (2005). A TRIZ-based method for new service design. Journal of Service Research, Vol 8, No 1., 48-66.

Chang, Y., Chien, Y., Yu, K., Chu, Y., \& Chen, Y. (2016). Effect of TRIZ on the creativity of engineering students. Thinking Skills and Creativity, Vol 19, 112-122.

Chechurin, L., \& Borgianni, Y. (2016). Understanding TRIZ through the review of top cited publications. Computers in Industry, Vol 82, 119-134.
Czinki, A., \& Hentschel, C. (2016). Solving complex problems and TRIZ, Vol $39,27-32$.

DetikHealth. (2011). Spidol Lebih Berbahaya Ketimbang Kapur Tulis. 1 Maret 2019, www.health.detik.com/beritadetikhealth/d-1573363/spidol-lebihberbahaya-ketimbang-kapur-tulis.

Ford, S., \& Minshall, T. (2019). Invited review article: Where and how $3 \mathrm{D}$ printing is used in teaching and education. Additive Manufacturing, 131-150.

Gadd, K. (2011). TRIZ for Engineers: enabling inventive problem solving, 486.

Gerberding, J. L. (2007). Toxicological Profile for Xylene. Atlanta.

Göçmen, Ö., \& Coşkun, H. (2019). The effects of the six thinking hats and speed on creativity in brainstorming. Thinking Skills and Creativity, Vol 31, 284-295.

Hartson, R., Pyla, P., Hartson, R., \& Pyla, P. (2019). Generative Design: Ideation, Sketching, and Critiquing. The UX Book, 293-325.

Ilevbare, I. M., Probert, D., \& Phaal, R. (2013). A review of TRIZ, and its benefits and challenges in practice. Technovation, Vol 33, No 2-3., 3037.

Lu, K., Qiao, X., \& Hao, N. (2019). Praising or keeping silent on partner's ideas: Leading brainstorming in particular ways. Neuropsychologia, Vol 124, 19-30.

Martin-erro, A., Dominguez, M., \& Espinosa, M. (2016). The Role of Sketching in Engineering Design and Its Presence on Engineering Education. 10th International Technology, Education and Development Conference, 34653471. 
Neghab, M., Hosseinzadeh, K., \& Hassanzadeh, J. (2015). Early liver and kidney dysfunction associated with occupational exposure to subthreshold limit value levels of benzene, toluene, and xylenes in unleaded petrol. Safety and Health at Work, Vol 6, No 4., 312-316.

Neghab, M., \& Stacey, N. H. (1997). In vitro interference with hepatocellular uptake of bile acids by xylene. Toxicology, Vol 120, No 1., 1-10.

Nies, E., \& Korinth, G. (2008). Commentary on "Penetration of benzene, toluene and xylenes contained in gasolines through human abdominal skin in vitro." Toxicology in Vitro, Vol 22, No 1., 275-277.

Paulus, P. B., Nakui, T., Putman, V. L., \& Brown, V. R. (2006). Effects of task instructions and brief breaks on brainstorming. Group Dynamics, Vol 10 No 3., 206-219.

Revilla, A. S., Pestana, C. R., Pardo-Andreu, G. L., Santos, A. C., Uyemura, S. A., Gonzales, M. E., \& Curti, C. (2007). Potential toxicity of toluene and xylene evoked by mitochondrial uncoupling. Toxicology in Vitro, Vol 21, No 5., 782-788.

Self, J. A. (2019). Communication through design sketches: Implications for stakeholder interpretation during concept design. Design Studies, Vol 63, 1-36.

Shroyer, K., Lovins, T., Turns, J., Cardella, M. E., \& Atman, C. J. (2018). Timescales and ideaspace: An examination of idea generation in design practice. Design Studies, Vol 57, 9-36.

Wetter-Edman, K., Vink, J., \& Blomkvist, J. (2018). Staging aesthetic disruption through design methods for service innovation. Design Studies, Vol 55, 5-26.

Yuan, F. (2004). A Typical Example of Innovative Design Based on the TRIZ. The TRIZ Journal. 